\title{
Impact of Continuous Positive Airway Pressure Treatment on Periodic Leg Movement Disorder in Patients with Obstructive Sleep Apnea Syndrome and Sulfur Mustard's Lung Injury \\ SS Mousavi ${ }^{1}$, E Vahedi ${ }^{2}$, M Shohrati ${ }^{3}$, Z Poursaleh $^{4}$
}

\begin{abstract}
Objective: Periodic limb movement disorder (PLMD) and obstructive sleep apnea (OSA) are prevalent sleep disorders in Sulfur Mustard (SM) patients. This study aimed to consider the relationship between PLMD frequency and arousal related to PLMD in SM-exposed and OSA patients before and after treatment with continuous positive airway pressure (CPAP).

Methods: In this descriptive analytic study, SM-exposed male cases $(n=64)$ with an age-matched group and OSA unexposed controls $(n=64)$ were enrolled. OSA severity based on apnea hypopnea index (AHI), PLMI and PLM-arousal-index (PLMAI) was monitored between two groups in baseline and after CPAP or BiPAP treatment.
\end{abstract}

Results: PLMD frequency in OSA and SM groups was 91.5\% and 95.5\%, respectively. In SM patients, there were statistical differences for PLMA $(p=0.01)$, PLMAI $(p=0.02)$, PLMS associated with respiratory events $(\mathrm{p}=0.041)$, and PLMS without arousal and respiratory events $(\mathrm{p}=0.001)$ after CPAP therapy. But in OSA group, PLMS index $(p=0.003)$, PLMS associated with respiratory events $(p=$ 0.001), PLMS without arousal and respiratory events $(p=0.001)$ were significantly different after CPAP therapy. After receiving CPAP, sleep quality in both groups was increased significantly (SM: P = 0.006, OSA: $\mathrm{P}=0.001)$. There were no significant differences between two groups.

Conclusion: This study demonstrated that PLMD in SM patients was high and CPAP therapy reduced all these events significantly. This may represent a protective and maintenance Treatment against sleeprelated breathing disorders in SM-exposed patients.

Keywords: Continuous positive airway pressure, obstructive sleep apnea, periodic leg movement disorder, sulfur mustard

From: ${ }^{1}$ Chemical Injuries Research Center, Baqiyatallah University of Medical Sciences, Tehran, Iran. ${ }^{2}$ Chemical Injuries Research Center, Baqiyatallah University of Medical Sciences, Tehran, Iran. ${ }^{3}$ Chemical Injuries Research Center, Baqiyatallah University of Medical Sciences, Tehran, Iran. ${ }^{4}$ Chemical Injuries Research Center, Baqiyatallah University of Medical Sciences, Tehran, Iran.

Correspondence: Mr E Vahedi, Chemical Injuries Research Center, Baqiyatallah University of Medical Sciences, Molla Sadra Ave., Vanak Sq 14359, Tehran, Iran. E-mail: Vahedi.bmsu@yahoo.com 


\section{INTRODUCTION}

Sulfur mustard, bis (2-chloroethyl) sulfide (SM), is a lethal chemical warfare (CWA) with high absorbance and alkylation properties, which affects several tissues such as the lungs, eyes and skin (1-4). Exposure to sulfur mustard (SM) leads to short- and long-term adverse effects in these organs. The highest unconventional application of SM occurred in Iran-Iraq war (1980-1988). During that period, it injured more than 100,000 Iranians, which one-third of them are still suffering from long-term effects. $(5,6)$. Cough, sputum, and shortness of breath are the main long-term effects of SM which were reported in $80 \%$ of Iranian patients after exposure to SM (6-9). Hemoptysis, feeling of pressure in the thorax, chest pain, and nocturnal dyspnea are the other common complications (10).

Respiratory tract injury is the most common late complication of SM inhalation that leads to pulmonary disorders. The main underlying pathology of SM patients is bronchiolitis obliterans (BO) and chronic obstructive pulmonary disease (COPD) (8, 11, 12). Lipid peroxidation, protein alkylation, nucleic acid alkylation, DNA breakage and repair, immune system induction and activation are also reported as cellular and molecular mechanisms of SM injury $(5,8,13,14)$. Sleep-related breathing disorder (SRBD) is a serious problem among SM exposed patients because it is associated with several unusual respiratory patterns such as obstructive sleep apnea (OSA), hypopnea, and respiratory effort related arousal (RERA).

Hypoventilation or reductions in gas exchange that occur during sleep are also included in SRBD $(15,16,17)$. OSA is a common respiratory disorder during sleep that characterized by apneas, and associated with a reduction in blood oxygen saturation. Each event of OSA typically lasts 20-40 seconds (18-20) and caused by obstruction of the upper airways (21). A recent assessment of polysomnography has shown that approximately onequarter to one-half of OSA patients are suffering from PLMD $(22,23)$. PLMD is a periodic movement disorder that occurs during sleep that characterized by repetitive leg movements, 
poor quality of sleep, and insomnia $(24,25)$. PLMD are more likely to occur in lower extremities and consist of stereotypical limb movements lasting from 0.5 to 10 seconds reaching amplitude of at least $25 \%$ of baselines toe dorsiflexion, occurring in runs of $\geq 4$ with an inner movement interval of 5 to 90 seconds during sleep. It is also poorly understood that why some OSA patients are severely sleepy, whereas others seem immune to this disorder. PLMD with OSA cause dopamine transmission system and sleep disturbances $(24,25)$.

Continuous positive airway pressure (CPAP) is an effective treatment for moderate to severe OSA and SM patients $(26,27)$. It keeps the airway open during sleep by delivering positive air pressure via a nasal mask or nasal pillows, which fit snugly in the nostrils. CPAP pressures are titrated to eliminate apneas and snoring in a follow-up polysomnogram for diagnostic purposes (27). Arousal induced by PLMD has been reported in COPD patients. CPAP therapy has been also showed to improve SRBD and quality of life in COPD patients, which is very similar to SM-lung patients (28). On the other hand, SM-exposed patients suffering from chronic respiratory complain more than two decades, and so they have some sleep problems such as poor quality of sleep, snoring, and daily somnolence $(27,29)$. To date, the relationship between PLMD frequency and arousal related to PLMD has not been reported in SM patients. Therefore, the purpose of the present study is to consider the effect of CPAP therapy on the number of PLM's and clinical symptoms in SM and OSA patients

\section{MATERIALS AND METHODS}

\section{Subjects and study design}

This study was conducted according to a parallel, prospective, cross-sectional, design from Jun 2012 to January 2013 in pulmonary department of Baqiyatallah Hospital, Tehran, Iran. This hospital provides medical cares for SM-exposed patients who injured during the Iraq- 
Iran war and maintains medical records from the patients. We examined data on $64 \mathrm{SM}$ injured patients and 64 OSA diagnosed patients in the age/sex-matched group, among the more than 100 OSA and 100 SM patients. We used polysomnographic evaluations for all participants. The advantages of CPAP or BiPAP were explained for patients and written consent form was obtained from all participants before recruitment.

\section{Exclusion and inclusion criteria}

SM-exposed male patients who have suffered from chronic obstructive respiratory disease and BO were enrolled in this study. The other group included patients who had OSA problem with any complaints of sleep disorders. These patients had Epworth Sleepiness Scale (ESS) score above 10 and were selected for polysomnography. They compared with an age-matched group of SM patients who had complaints of sleep problems. Patients who had the following criteria were excluded from the study: acute bronchiolitis and/or pneumonia, history of pulmonary tuberculosis or resection of one or more lobes, fibromyalgia, musculoskeletal disease, and exposure to other toxin, central sleep apnea, hematologic disorders, neurologic disorders, cardiovascular disease, and participating in simultaneous clinical trials. Patients were also excluded if they were using any type of medications that may induce PLM disorder (e.g., dopaminergic medications, opiates, benzodiazepines, and tricyclic antidepressants). Patients with autoimmune induced diseases such as type 1 diabetes mellitus (T1DM), or rheumatoid arthritis (RA), and acute upper respiratory tract infections, were excluded as well.

\section{Sleep parameters and polysomnographic evaluation}

All patients in the study population underwent an overnight polysomnographic (Alice 5, Respironics Company, Pensylvania 2006) evaluation for sleep abnormalities (insufficient sleep, sleep fragmentation, daytime fatigue, and incompetent sleep) at the sleep unit of Baqiyatallah Hospital. The diagnoses of OSA and PLMS were confirmed by PSG that started 
at 22:00 and ended at 6:00am. For PSG, subjects were slept in private, electrically shielded, sound-attenuated and temperature-controlled bedrooms. Standard surface electrodes were used to record electroencephalographic (EEG), electrooculographic, electromyographic (EMG) (submentalis and anterior tibialis), and electrocardiographic activities. Apneas and hypopneas were scored according to modifications of the American Academy of Sleep Medicine Task Force criteria (30). Respiratory evaluations were scored for the presence of apneas (10-s, or longer, cessation in nasal-oral airflow). Airflow was monitored by nasal-oral thermocouples, and respiratory efforts were monitored through thoracic and abdominal movements. Apnea was scored when there was a cessation of airflow with duration of 10 s or more. Obstructive apnea was diagnosed if an effort to breathe was detected by abdominal movement, thoracic movement, or intercostal EMG activity during the episode. A central apnea is defined when a cessation of airflow was detected for at least 10 s during which there was no indication of respiratory effort. Blood oxygen saturation was measured by pulse oximetry using a finger probe.

PLMS were recorded from 2 surface electromyographic electrodes positioned 2 to 4 cm apart over the belly of the tibialis anterior muscle of each lower limb (31). Leg movements that occurred as part of general body movements in association with EEG arousals following obvious apneas or hypopneas were not scored as PLMS (32). The complete record was scored manually for sleep stage, arousals, apneas, hypopneas, total periodic leg movements, and periodic leg movements associated with arousals.

All entered patients were treated with CPAP, which was delivered via a full face mask in which a mask is worn over the nose and mouth during sleep. Sleep study was performed in two segments including the first (first $4 \mathrm{~h}$ of sleep (SS1)) without CPAP and the second segments (second $4 \mathrm{~h}$ of sleep (SS2)) with CPAP titration if indicated. Comparison of the two segments and two groups (SM and OSA) was also performed. The CPAP titration was begun 
at $4 \mathrm{~cm} \mathrm{H}_{2} \mathrm{O}$ and was adjusted in increments of $1 \mathrm{~cm} \mathrm{H}_{2} \mathrm{O}$ until apneas, hypopneas and snoring were eliminated and isolated electroencephalographic arousals were minimized.

After obtaining demographic information as well as completed ESS questionnaire, polysomnography was done for all patients. Detailed sleep parameters including: total sleep time (TST), sleep and rapid eye movement (REM) latency, sleep efficiency, REM and slow wave sleep (SWS) percentages, arousal index, periodic limb movement index, periodic limb movement arousals, oxygen saturation nadir, apnea-hypopnea index (AHI) and end tidal carbon dioxide $\left(\mathrm{ETCO}_{2}\right)$ were evaluated (33).

After treatment with CPAP or BiPAP, these variables were evaluated in the both groups. Finally, the relationship between PLMD frequency with OSA and SM exposure were determined and compared. In this study, the percentages of patients who had PLMS index above $20 \%$ before and after CPAP therapy were compared between two groups. Total PLMS, PLMS index, PLMS associated with arousal, PLMS associated with respiratory events, PLMS without arousal and respiratory events compared in the SM and OSA groups, before and after CPAP therapy.

\section{Ethical considerations}

This study was approved by Ethical committee of BMSU. Potential volunteers were informed about the purpose and procedure of the study and only volunteers who signed an informed consent were recruited. The informed consent tells patients that they have a right to leave the study at any time.

\section{Statistical analysis}

All quantitative data were analyzed using SPSS v16 (SPSS Inc, Chicago, IL, USA) and are shown as mean \pm SD. A Kolmogorove-Smirnov test was performed to examine the normality of data. Quantitative parameters were expressed as mean $\pm \mathrm{SD}$ and compared using a 
Student's t-test. Independent and paired sample t-tests, analysis of variance (ANOVA), a Mann-Whitney Test, and a Kruskal-Wallis test were used to analyze continuous variables. There were no missing values. Due to the small sample size, a Bootstrap method was used. The Spearman's rank correlation test was employed to determine the association between two variables. P-Values $<0.05$ were considered as significant difference.

\section{RESULTS}

\section{Study population}

As we depicted in a flowchart, of 200 eligible patients, 72 patients were excluded from the further analysis because of complement disorders and reluctance to cooperate in survey (figure 1). Finally, we entered 128 male patients in this study, which were divided into two age/sex-matched groups including SM $(n=64)$ and OSA $(n=64)$ patients. Demographic and clinical characteristics of all patients in the both study groups are summarized in table 1 . No significant differences were observed for baseline demographic characteristics between the two groups.

\section{Polysomnographic variables characteristics}

Table 2 shows the polysomnographic variables in each group before and after CPAP therapy. There is a significant difference between $\mathrm{SM}$ and OSA groups for TST $(\mathrm{P}=0.03)$, SE $(\mathrm{P}=0.004)$ and PLMAI $(\mathrm{P}=0.001)$ before CPAP treatment $(\mathrm{P}<0.05)$. After CPAP therapy, only sleep onset latency (SOL) $(\mathrm{P}=0.01)$ and PLMAI $(\mathrm{P}=0.004)$ were significantly different between two groups $(\mathrm{P}<0.05)$. The average of total sleep times after CPAP therapy had been increased significantly in both groups.

After CPAP titration, the mean of SOL in the SM and OSA groups was reduced nearly seven and three times, respectively $(\mathrm{P}<0.001)$. In the SM group, SE $(\%)$, PLMA, and 
PLMAI were increased significantly $(\mathrm{P}<0.05)$. The PLMA and SE were significantly increased in OSA group $(\mathrm{P}<0.001)$; while the PLMAI was reduced $(\mathrm{P}=0.004)$. There was no significant difference in mean of TST before and after CPAP therapy in the both groups. The prevalence of AHI in the SM and OSA groups was $65.95 \%$ and $3.91 \%$, respectively. The mean of AHI before CPAP therapy in the SM and OSA groups was $21.20 \pm 17.44$ and $25.19 \pm 13.34$, respectively. This difference was not significant between the two groups $(\mathrm{P}=0.23)$. Also, the mean of AHI after CPAP in the SM and OSA groups was $8.27 \pm 7.82$ and $10.04 \pm 7.88$, respectively. This difference was not significant between the two groups $(\mathrm{P}=0.32)$. The percentage of PLMS index above 20, in the SM and OSA groups before CPAP was $34.78 \%$ and $50 \%$, respectively.

\section{PLMS characteristics}

The mean of PLMS characteristics from patients in the both groups are shown in Table 3. There was no significant difference between the two groups regarding the PLMS data before and after CPAP. However, a significant difference was observed in the mean of PLMS without arousal and respiratory events $(\mathrm{P}=0.001)$ and PLMS associated with respiratory events before and after CPAP in SM exposed group. A significant difference was also found for the means of PLMS associated with arousal $(\mathrm{P}=0.003)$, PLMS associated with respiratory events $(\mathrm{P}=0.007)$, PLMS without arousal and respiratory events $(\mathrm{P}=0.001)$, and PLMS index $(\mathrm{P}=0.001)$ in OSA group.

\section{PLMS > 20 characteristics}

The percentages of patients who had PLMS index above $20 \%$ before and after CPAP therapy were also compared with each other. In the both study groups, PLMS index, PLMS associated with arousal, PLMS associated with respiratory events, PLMS without arousal and respiratory events were compared before and after CPAP therapy. These data are summarized 
in Table 4. There was no significant difference for all evaluated PLMS indexes above 20\% $(P \geq 0.05)$ between two groups after and before CPAP therapy. The percentage of patients in the SM and OSA groups who had PLMS index above 20\% before the CPAP therapy was $34.78 \%$ and $50 \%$, respectively. However, after CPAP therapy this percentage was decreased to $19.56 \%$ and $30.43 \%$, respectively. Interestingly, there was no significant difference between the two groups, after and before CPAP therapy $(\mathrm{P}=0.93)$. The percentage of patients, who had PLMS associated with arousal above $20 \%$, was $51.52 \pm 17.23$ and $40.71 \pm 20.19$ in the SM and OSA groups, respectively. The difference between the two groups was not statistically significant $(\mathrm{P}=0.21)$. But after CPAP therapy, the percentage of patients who had PLMS associated with arousal above $20 \%$, was changed to $43.9 \%$ and $38.58 \%$ in the SM and OSA groups, respectively. This difference was not significant between two groups $(\mathrm{P}=0.51)$. The percentage of patients, who had the PLMS associated with arousal above $20 \%$ before CPAP, was $19.56 \%$ and $30.43 \%$ in the SM and OSA groups, respectively. However, it had been increased to $28.26 \%$ and $41.3 \%$ in the SM and OSA groups, respectively. Also there was no significant difference between the two groups, after and before CPAP therapy $(\mathrm{P} \geq 0.05)$. The percentage of patients who had the PLMS associated with respiratory events $>20 \%$ before CPAP, was $10.86 \%$ in the both groups. It had been increased to $67.39 \%$ and $82.6 \%$ in the SM and OSA groups respectively. We didn't find a significant difference between the two groups, after and before CPAP therapy $(\mathrm{P} \geq 0.05)$.

\section{DISCUSSION}

In this study we evaluated the relationship between PLMD frequency and arousal related to PLMD in the SM and OSA patients before and after CPAP therapy. To the best of our knowledge, there is only one study that considered the effects of CPAP therapy on PLMD in 
SM patients (15). Our data showed that the frequency of PLMI-PLMAI in SM patients was higher when it compared to patients with moderate OSA. These results noted a high frequency of PLMD in SM and OSA groups. Furthermore, PLMS Index in OSA patients was declined significantly after CPAP therapy; however, in SM patients we didn't observe a significant change. PLMS associated with respiratory events in each group had been decreased significantly after CPAP therapy, but there was no significant difference between the two groups. PLMS associated with arousal (PLMAI) was also increased significantly in the OSA group $(\mathrm{P}=0.003)$, but there was no significant change in the $\mathrm{SM}$ group after receiving CPAP. Sleep quality was raised significantly after CPAP therapy in the both groups (SM: $\mathrm{P}=0.006$, OSA: $\mathrm{P}=0.001)$.

In a study by Charokopos et al, they have compared the PLMD in the COPD and OSA patients. They have reported a significant increase in mean of PLMIA among COPD group. PLMS associated with arousal was also seen in patients with COPD (28). In our study, SM patients could be considered as a subset of patients with COPD due to similarities in respiratory disease $(34,35)$. Several studies have recently reported that patients with Overlap Syndrome (COPD and OSA), have higher interest rates of hypoxia and hypercapnia than COPD patients (36-38). In this study the prevalence of AHI in patients who exposed to SM was higher than patients with OSA $(95.5 \%$ vs $91.5 \%)$. Therefore, SM patients are component of Over Lap Syndrome patients. Previous studies have reported that inflammatory stimuli during sleep and loss of pulmonary function in patients with COPD are the main reasons for OSA in the Over Lap Syndrome patients (38-40). Also cardiovascular, hematologic and pulmonary function disorders are more common in SM and COPD patients who have also sleep hypoxia. Oxygen therapy is the main treatment of COPD patients with OSA. In addition, CPAP is a useful adjunctive therapy for Over Lap Syndrome patients (4143). In our previous study, the prevalence of nocturnal hypoxia in COPD patients was 
reported $89 \%$, in which nocturnal hypoxia was decreased significantly after CPAP therapy (15).

In the current study, the average of total sleep times after CPAP therapy in OSA and SM patients was increased to $17.79 \%$ and $15.85 \%$, respectively. Factors such as disorders in oxygen saturation, arousal reduction, weakness of respiratory muscle, increase in airway resistance, mechanical respiratory dysfunction (such as dysfunction of the diaphragm and increasing of functional residual capacity (FRC)), and reduction in ventilation response to hypoxia and hypercapnia are the main reasons for respiratory disorders during sleep in COPD patients (44-46). Therefore, we can improve the sleep quality of COPD and SM patients with improve of lung mechanical function. In other word, respiratory parameters in patients with obstructive sleep apnea who don't have PLMD are somehow worse than patients who have OSA and PLMD. Other previous studies confirmed that PLMD in patients exaggerates respiratory symptoms, independent from OSA $(47,48)$.

In our study, adverse respiratory events were significantly reduced after CPAP therapy and that there were no significant differences with OSA group. This highlights the fact that in the pathogenesis of SRBD in mustard-exposed patients, the role of upper airways is more important than the lower airways and bronchiolitis.

One limitation of this study was lack of a control group free of both RLS and PLMS. On the other hand, the prevalence of OSA and PLMS in SM patients was $95.5 \%$ and $93.8 \%$, respectively, which was more than expected. To determine overall prevalence, it is necessary to conduct additional studies with more samples, as well as evaluate the severity of obstructive sleep disorders and relationship with PLMD in compare with control groups.

Due to the high cost of treatment and the severity of nocturnal hypoxia in SM patients and the high prevalence of OSA in this group, it's necessary to consider sleep disorder seriously in 
these patients and evaluate new therapeutic approaches to reduce PLMD and other related disorders.

\section{CONCLUSIONS}

In conclusion, the prevalence of PLMD was high in patients exposed to SM, suggesting this disorder is not solely associated with respiratory problems. This study underscores importance of recognizing PLMD as a concurrent sleep disorder on several subjects with OSA presenting for CPAP titration. In order to manage and treat this condition, more data are needed to understand the severity of this issue. Moreover, complementary molecular studies along with large sample sizes are necessary to be conducted in further investigations.

\section{ACKNOWLEDGMENT}

The authors would like to express their appreciation to appreciate Baqiyatallah University of Medical Science for its financial support. 


\section{REFERENCES}

1. R.C. Malhotra KG, K. Sugendran and R.V. Swamy. Chemistry and Toxicology of Sulphur Mustard: A Review. Defence Science Journal, 1999; 49:97-116.

2. Shadboorestan A. Commentary on: a review on delayed toxic effects of sulfur mustard in Iranian veterans. Daru 2012; 20:99.

3. Fallis IA, Griffiths PC, Cosgrove T, Dreiss CA, Govan N, Heenan RK, et al. Locusspecific microemulsion catalysts for sulfur mustard (HD) chemical warfare agent decontamination. J Am Chem Soc 2009; 131:9746-9755.

4. Dacre JC, Goldman M. Toxicology and pharmacology of the chemical warfare agent sulfur mustard. Pharmacol Rev 1996; 48:289-326.

5. Ghanei M, Harandi AA. Molecular and cellular mechanism of lung injuries due to exposure to sulfur mustard: a review. Inhal Toxicol 2011; 23:363-371.

6. Ghanei M, Poursaleh Z, Harandi AA, Emadi SE, Emadi SN. Acute and chronic effects of sulfur mustard on the skin: a comprehensive review. Cutan Ocul Toxicol 2010; 29:269-277.

7. Bagheri MH, Hosseini SK, Mostafavi SH, Alavi SA. High-resolution CT in chronic pulmonary changes after mustard gas exposure. Acta Radiol 2003; 44:241-245.

8. Ghanei M, Harandi AA. Long term consequences from exposure to sulfur mustard: a review. Inhal Toxicol 2007; 19:451-456.

9. Emami MH, Talaei M, Panahi Y, Saburi A, Ghanei M. Efficacy of omeprazole on cough, pulmonary function and quality of life of patients with sulfur mustard lung injury: A placebo-control, cross-over clinical trial study. J Res Med Sci 2014; 19:1027-1033. 
10. Ghanei M, Mokhtari M, Mohammad MM, Aslani J. Bronchiolitis obliterans following exposure to sulfur mustard: chest high resolution computed tomography. Eur J Radiol 2004; 52:164-169.

11. Aghanouri R, Ghanei M, Aslani J, Keivani-Amine H, Rastegar F, Karkhane A. Fibrogenic cytokine levels in bronchoalveolar lavage aspirates 15 years after exposure to sulfur mustard. Am J Physiol Lung Cell Mol Physiol 2004; 287:L1160-1164.

12. Bijani K, Moghadamnia AA. Long-term effects of chemical weapons on respiratory tract in Iraq-Iran war victims living in Babol (North of Iran). Ecotoxicol Environ Saf 2002; 53:422-424.

13. Ray R, Keyser B, Benton B, Daher A, Simbulan-Rosenthal CM, Rosenthal DS. Sulfur mustard induces apoptosis in cultured normal human airway epithelial cells: evidence of a dominant caspase-8-mediated pathway and differential cellular responses. Drug Chem Toxicol 2008; 31:137-148.

14. Emad A, Rezaian GR. Immunoglobulins and cellular constituents of the BAL fluid of patients with sulfur mustard gas-induced pulmonary fibrosis. Chest 1999; 115:13461351.

15. Vahedi E, Taheri S, Alaedini F, Poursaleh Z, Ameli J, Ghanei M. Correlations of sleep disorders with severity of obstructive airway disease in mustard gas-injured patients. Sleep Breath 2012; 16:443-451.

16. Fleetham J, West P, Mezon B, Conway W, Roth T, Kryger M. Sleep, arousals, and oxygen desaturation in chronic obstructive pulmonary disease. The effect of oxygen therapy. Am Rev Respir Dis 1982; 126:429-433.

17. Kinsman RA, Yaroush RA, Fernandez E, Dirks JF, Schocket M, Fukuhara J. Symptoms and experiences in chronic bronchitis and emphysema. Chest 1983; 83:755-761. 
18. Li Q, Wang Q. [Sleep related breathing disorders in international classification of sleep disorders-3]. Zhonghua Jie He He Hu Xi Za Zhi 2014; 37:883-884.

19. Morrison I, Buskova J, Nevsimalova S, Douglas NJ, Riha RL. Diagnosing narcolepsy with cataplexy on history alone: challenging the International Classification of Sleep Disorders (ICSD-2) criteria. Eur J Neurol 2011; 18:1017-1020.

20. Shiina K, Tomiyama H, Takata Y, Yoshida M, Kato K, Nishihata Y, et al. Overlap syndrome: additive effects of COPD on the cardiovascular damages in patients with OSA. Respir Med 2012; 106:1335-1341.

21. Soriano JB, Yanez A, Renom F, de la Pena M, Gomez A, Duro R, et al . Set-up and pilot of a population cohort for the study of the natural history of COPD and OSA: the PULSAIB study. Prim Care Respir J 2010; 19:140-147.

22. Chervin RD. Periodic leg movements and sleepiness in patients evaluated for sleepdisordered breathing. Am J Respir Crit Care Med 2001; 164:1454-1458.

23. Al-Alawi A, Mulgrew A, Tench E, Ryan CF. Prevalence, risk factors and impact on daytime sleepiness and hypertension of periodic leg movements with arousals in patients with obstructive sleep apnea. J Clin Sleep Med 2006; 2:281-287.

24. Rijsman RM, de Weerd AW. Secondary periodic limb movement disorder and restless legs syndrome. Sleep Med Rev 1999; 3:147-158.

25. Stiasny K, Oertel WH, Trenkwalder C. Clinical symptomatology and treatment of restless legs syndrome and periodic limb movement disorder. Sleep Med Rev 2002; 6:253-265.

26. Rauscher H, Popp W, Wanke T, Zwick H. Breathing during sleep in patients treated for obstructive sleep apnea. Nasal CPAP for only part of the night. Chest 1991; 100:156-159. 
27. Vahedi E, Fazeli Varzaneh AR, Ghanei M, Afsharpaiman S, Poursaleh Z. The effect of nightly nasal CPAP treatment on nocturnal hypoxemia and sleep disorders in mustard gas-injured patients. Sleep Breath 2014; 18:741-748.

28. Charokopos N, Leotsinidis M, Pouli A, Tsiamita M, Karkoulias K, Spiropoulos K. Periodic limb movement during sleep and chronic obstructive pulmonary disease. Sleep Breath 2008; 12:155-159.

29. Khateri S, Ghanei M, Keshavarz S, Soroush M, Haines D. Incidence of lung, eye, and skin lesions as late complications in 34,000 Iranians with wartime exposure to mustard agent. J Occup Environ Med 2003; 45:1136-1143.

30. Sleep-related breathing disorders in adults: recommendations for syndrome definition and measurement techniques in clinical research. The Report of an American Academy of Sleep Medicine Task Force. Sleep 1999; 22:667-689.

31. Stucki A, Cieza A, Michel F, Stucki G, Bentley A, Culebras A, et al. Developing ICF Core Sets for persons with sleep disorders based on the International Classification of Functioning, Disability and Health. Sleep Med 2008; 9:191-198.

32. Schenck $\mathrm{CH}$, Mahowald MW. Motor dyscontrol in narcolepsy: rapid-eye-movement (REM) sleep without atonia and REM sleep behavior disorder. Ann Neurol 1992; 32:3-10.

33. Bokkala S, Napalinga K, Pinninti N, Carvalho KS, Valencia I, Legido A, et al. Correlates of periodic limb movements of sleep in the pediatric population. Pediatr Neurol 2008; 39:33-39.

34. Balali-Mood M, Hefazi M. The pharmacology, toxicology, and medical treatment of sulphur mustard poisoning. Fundam Clin Pharmacol 2005; 19:297-315.

35. Hefazi M, Attaran D, Mahmoudi M, Balali-Mood M. Late respiratory complications of mustard gas poisoning in Iranian veterans. Inhal Toxicol 2005; 17:587-592. 
36. Claman DM, Redline S, Blackwell T, Ancoli-Israel S, Surovec S, Scott N, et al, Study of Osteoporotic Fratures Research G. Prevalence and correlates of periodic limb movements in older women. J Clin Sleep Med 2006; 2:438-445.

37. Aurora RN, Kristo DA, Bista SR, Rowley JA, Zak RS, Casey KR, et al, American Academy of Sleep M. The treatment of restless legs syndrome and periodic limb movement disorder in adults--an update for 2012: practice parameters with an evidence-based systematic review and meta-analyses: an American Academy of Sleep Medicine Clinical Practice Guideline. Sleep 2012; 35:1039-1062.

38. Shteinberg M, Weiler-Ravel D, Adir Y. [The overlap syndrome: obstructive sleep apnea and chronic obstructive pulmonary disease]. Harefuah 2009; 148:333-336, 348.

39. Hiestand D, Phillips B. The overlap syndrome: chronic obstructive pulmonary disease and obstructive sleep apnea. Crit Care Clin 2008; 24:551-563, vii.

40. Weitzenblum E, Chaouat A, Kessler R, Canuet M. Overlap syndrome: obstructive sleep apnea in patients with chronic obstructive pulmonary disease. Proc Am Thorac Soc 2008; 5:237-241.

41. O'Brien A, Whitman K. Lack of benefit of continuous positive airway pressure on lung function in patients with overlap syndrome. Lung 2005; 183:389-404.

42. Crinion SJ, McNicholas WT. Sleep-related disorders in chronic obstructive pulmonary disease. Expert Rev Respir Med 2014; 8:79-88.

43. Brown LK. Sleep-related disorders and chronic obstructive pulmonary disease. Respir Care Clin N Am 1998; 4:493-512.

44. Lo Coco D, Mattaliano A, Lo Coco A, Randisi B. Increased frequency of restless legs syndrome in chronic obstructive pulmonary disease patients. Sleep Med 2009; 10:572-576. 
45. Valipour A, Lavie P, Lothaller H, Mikulic I, Burghuber OC. Sleep profile and symptoms of sleep disorders in patients with stable mild to moderate chronic obstructive pulmonary disease. Sleep Med 2011; 12:367-372.

46. Fry JM, DiPhillipo MA, Pressman MR. Periodic leg movements in sleep following treatment of obstructive sleep apnea with nasal continuous positive airway pressure. Chest 1989; 96:89-91.

47. Iriarte J, Alegre M, Irimia P, Urriza J, Artieda J. [Clinical relevance of periodic limb movements during sleep in obstructive sleep apnea patients]. Rev Neurol 2000; 30:101-104.

48. Kinge E, Ulfberg J. [Sleep-related movement disorders]. Tidsskr Nor Laegeforen 2009; 129:1888-1891. 
Table 1: Demographic and baseline characteristics of the study populations

\begin{tabular}{llll}
\hline Variable & SM $(\mathbf{N}=\mathbf{4 6})$ & OSA $(\mathbf{N}=46)$ & P \\
\hline Age $(\mathrm{yr})$ & $48.23 \pm 7.56$ & $48.65 \pm 11.72$ & 0.84 \\
Weight $(\mathrm{g})$ & $86.77 \pm 17.53$ & $93.10 \pm 18.83$ & 0.75 \\
Height $(\mathrm{cm})$ & $169.10 \pm 8.19$ & $168.54 \pm 9.23$ & 0.09 \\
BMI $(\mathrm{kg} / \mathrm{m} 2)$ & $30.47 \pm 5.62$ & $32.09 \pm 15.00$ & 0.1
\end{tabular}

All data expressed as mean \pm SD (range); Abbreviations: Obestractive sleep apnea (OSA); Sulfur mustard (SM); Body mass index (BMI).

Table 2: Comparison of polysomnographic variables in the each group; Pre- and post-CPAP therapy

\begin{tabular}{|c|c|c|c|c|c|}
\hline Variables & CPAP & SM $(n=64)$ & $\mathbf{P}^{*}$ & OSA $(n=64)$ & $\mathbf{P}^{*}$ \\
\hline TST & $\begin{array}{l}\text { Per } \\
\text { Post }\end{array}$ & $\begin{array}{l}222.81 \pm 52.61 \\
257.62 \pm 45.09\end{array}$ & 0.80 & $\begin{array}{r}210.51 \pm 47.08^{\mathrm{a}} \\
240.86 \pm 57.56^{\mathrm{NS}}\end{array}$ & 0.057 \\
\hline SOL (min) & $\begin{array}{l}\text { Per } \\
\text { Post }\end{array}$ & $\begin{array}{r}21.10 \pm 3.14 \\
3.10 \pm 0.9\end{array}$ & 0.001 & $\begin{array}{r}19.77 \pm 3.80^{\mathrm{NS}} \\
8.33 \pm 2.23^{\mathrm{a}}\end{array}$ & 0.006 \\
\hline SE $(\%)$ & $\begin{array}{l}\text { Per } \\
\text { Post }\end{array}$ & $\begin{array}{l}87.95 \pm 9.95 \\
91.50 \pm 9.16\end{array}$ & 0.21 & $\begin{array}{r}78.72 \pm 15.45^{\text {a }} \\
88.56 \pm 12.24^{\mathrm{NS}}\end{array}$ & 0.001 \\
\hline PLMA & $\begin{array}{l}\text { Per } \\
\text { Post }\end{array}$ & $\begin{array}{l}3.30 \pm 2.76 \\
4.39 \pm 4.40\end{array}$ & 0.01 & $\begin{array}{l}4.84 \pm 8.75^{\mathrm{NS}} \\
6.84 \pm 8.56^{\mathrm{NS}}\end{array}$ & 0.004 \\
\hline PLMAI & $\begin{array}{l}\text { Per } \\
\text { Post }\end{array}$ & $\begin{array}{r}21.09 \pm 2.42 \\
22.37 \pm 19.07\end{array}$ & 0.02 & $\begin{array}{l}48.09 \pm 33.61^{b} \\
40.30 \pm 34.69^{b}\end{array}$ & 0.004 \\
\hline
\end{tabular}

All data expressed as mean \pm SD (range); Abbreviations: Continuous positive airway pressure (CPAP); Sulfur mustard (SM); Obstructive sleep apnea (OSA); Total sleeps time (TST); Sleep onset latency (SOL); Sleep efficiency (SE); Periodic limb movement arousal index ( $\geq 5$ per s) (PLMA); Periodic limb movement arousal index (PLMAI); a: $\mathrm{P}<0.05$ and b: $\mathrm{P}<0.001$ with SM group , NS: Not significant. ${ }^{*}$ Independent-sample Student's t-test. 
Table 3: Comparison of PLMS variables in the each group; Pre- and post-CPAP therapy

\begin{tabular}{|c|c|c|c|c|c|}
\hline Variables & CPAP & SM $(n=64)$ & $\mathbf{P}^{*}$ & OSA $(n=64)$ & $\mathbf{P}^{*}$ \\
\hline Total PLMS & $\begin{array}{l}\text { Per } \\
\text { Post }\end{array}$ & $\begin{array}{l}198.54 \pm 28.39 \\
276.87 \pm 57.66\end{array}$ & 0.89 & $\begin{array}{l}146.23 \pm 47.17^{\mathrm{NS}} \\
291.22 \pm 19.46^{\mathrm{NS}}\end{array}$ & 0.16 \\
\hline $\begin{array}{l}\text { leg } \\
\text { movements }\end{array}$ & Per & $134.40 \pm 98.62$ & & $141.57 \pm 13.84 \mathrm{NS}$ & \\
\hline $\begin{array}{l}\text { that meets the } \\
\text { criteria of } \\
\text { PLMS }\end{array}$ & Post & $161.06 \pm 30.75$ & 0.54 & $128.75 \pm 17.22 \mathrm{NS}$ & 0.15 \\
\hline & Per & $33.78 \pm 4.60$ & & $45.59 \pm 4.64^{\mathrm{NS}}$ & \\
\hline PLMS index & Post & $35.73 \pm 6.89$ & 0.20 & $29.75 \pm 34.27^{\mathrm{NS}}$ & 0.015 \\
\hline $\begin{array}{l}\text { PLMS } \\
\text { associated } \\
\text { with arousal }\end{array}$ & $\begin{array}{l}\text { Per } \\
\text { Post }\end{array}$ & $\begin{array}{r}20.07 \pm 2.42 \\
20.66 \pm 21.86\end{array}$ & 0.31 & $\begin{array}{l}18.97 \pm 9.22^{\mathrm{NS}} \\
26.26 \pm 2.31^{\mathrm{NS}}\end{array}$ & 0.003 \\
\hline $\begin{array}{l}\text { PLMS } \\
\text { associated } \\
\text { with } \\
\text { respiratory } \\
\text { events }\end{array}$ & Post & $\begin{array}{l}37.34 \pm 6.31 \\
22.26 \pm 5.48\end{array}$ & 0.041 & $\begin{array}{c}36.67 \pm 6.42^{\mathrm{NS}} \\
16.38 \pm 47.54^{\mathrm{NS}}\end{array}$ & 0.001 \\
\hline $\begin{array}{l}\text { PLMS without } \\
\text { arousal and } \\
\text { respiratory } \\
\text { events }\end{array}$ & $\begin{array}{l}\text { Per } \\
\text { Post } \\
\end{array}$ & $\begin{array}{l}165.48 \pm 24.85 \\
391.73 \pm 68.89 \\
\end{array}$ & 0.001 & $\begin{array}{r}93.06 \pm 17.97^{b} \\
228.46 \pm 27.49^{b}\end{array}$ & 0.001 \\
\hline
\end{tabular}

All data expressed as mean \pm SD (range); Abbreviations: Continuous positive airway pressure (CPAP); Sulfur mustard (SM); Obstructive sleep apnea (OSA); Periodic limb movement arousal index ( $\geq 5$ per s) (PLMA); Periodic limb movement arousal index (PLMAI); a: $\mathrm{P}<0.05$ and b: $\mathrm{P}<0.001$ with SM group, NS: Not significant. ${ }^{*}$ Independent-sample Student's t-test.

Table 4. Comparison of PLMS $>20$ variables in the each group; Pre- and post-CPAP therapy.

\begin{tabular}{llrrl}
\hline Variables & CPAP & SM (n=64) & OSA (n=64) & P* \\
\hline PLMS index & Per & $72.44 \pm 36.48$ & $71.27 \pm 45.12$ & 0.53 \\
\hline & Post & $79.37 \pm 26.92$ & $61.31 \pm 9.66$ & 0.93 \\
$\begin{array}{l}\text { PLMS associated } \\
\text { with arousal }\end{array}$ & Per & $51.52 \pm 17.23$ & $40.71 \pm 20.19$ & 0.2 \\
& Post & $43.90 \pm 20.37$ & $38.58 \pm 25.14$ & 0.51 \\
\hline $\begin{array}{l}\text { PLMS associated } \\
\text { with } \\
\text { events }\end{array}$ & Per & $90.15 \pm 22.24$ & $75.73 \pm 17.53$ & 0.61 \\
\hline All & Post & $109.40 \pm 45.33$ & $103.80 \pm 49.35$ & 0.93
\end{tabular}

All data expressed as mean \pm SD (range); Abbreviations: Continuous positive airway pressure (CPAP); Sulfur mustard (SM); Obstructive sleep apnea (OSA); periodic limb movements of sleep (PLMS); a: $\mathrm{P}<0.05$ and $\mathrm{b}: \mathrm{P}<0.001$ with $\mathrm{SM}$ group, NS: Not significant.*Independent-sample Student's t-test. 


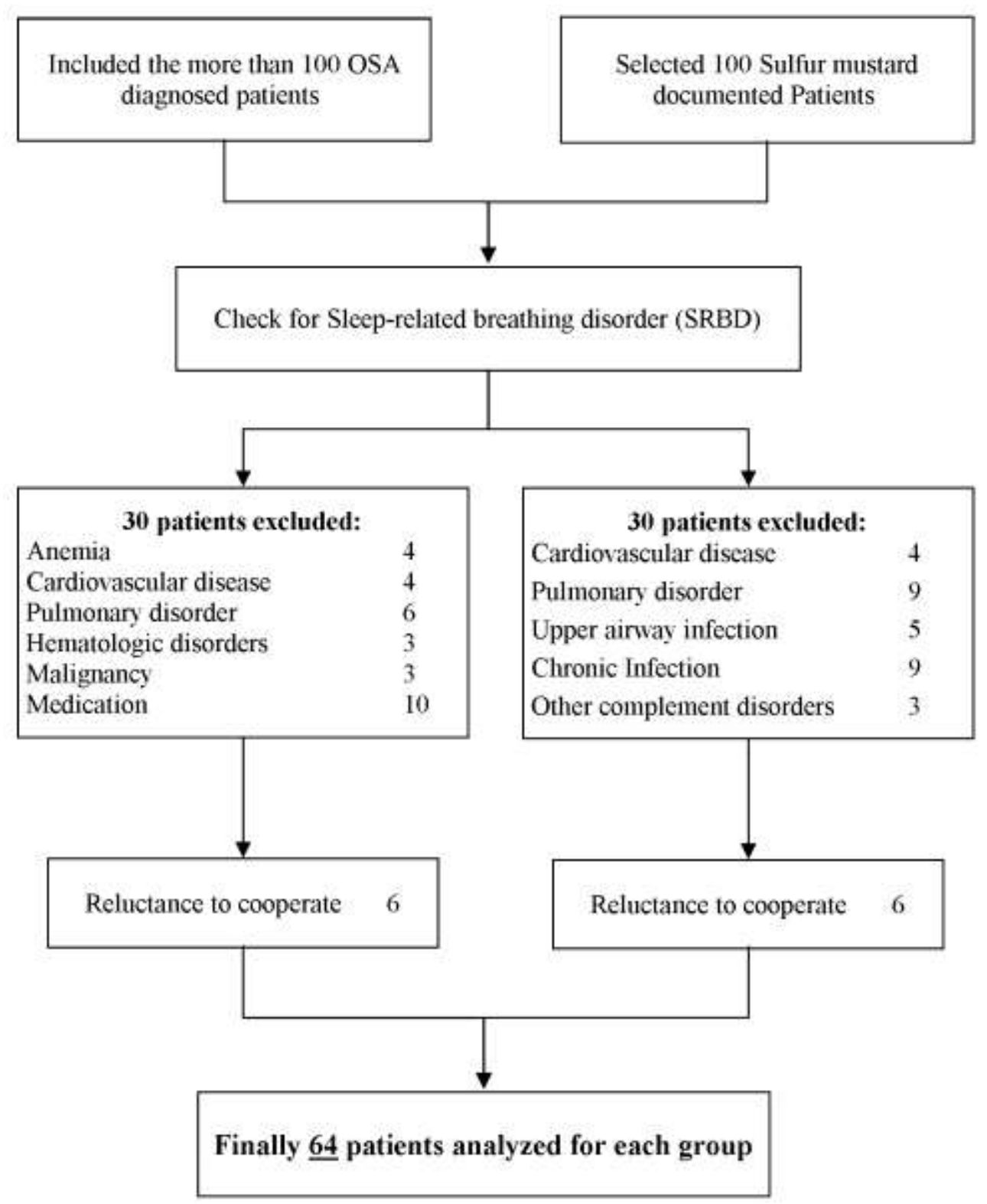

Figure: Flow chart of patient selection 